International Journal of Health Sciences
Available online at www.sciencescholar.us
Vol. 6 No. 1, April 2022, pages: 11-20
e-ISSN: 2550-696X, p-ISSN: 2550-6978
https://doi.org/10.53730/ijhs.v6n1.2981

\title{
Internet Technology as One of Distance Education during Pandemic
}

\author{
(2) CrossMark

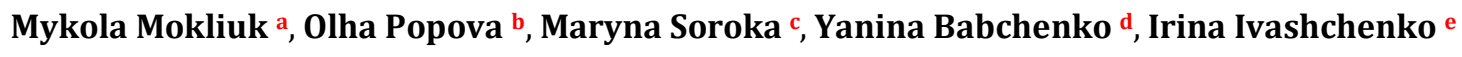 \\ Manuscript submitted: 5 August 2021, Manuscript revised: 18 November 2021, Accepted for publication: 15 December 2021
}

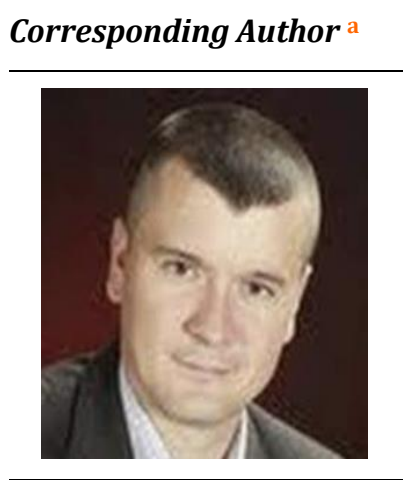

Keywords

distance education; education sector; education system; educational practice; educational process; pandemic;

\begin{abstract}
The article aims at allowing you to deepen the knowledge of the program material on computer science and, as a consequence, will increase the efficiency of the educational process as a whole during a pandemic, will increase the motivation of students to the subject; will allow developing students' abilities for self-development, self-education. Based on the purpose, subject, hypothesis of the research, the following tasks were solved: scientific methodological and pedagogical literature on the topic of research was studied; revealed the content and essence of Internet technologies; an Internet resource has been developed that allows organizing the process of distance learning in informatics; tested the effectiveness of its use in the process of teaching computer science to students. The practical significance of the study lies in the creation of an educational Internet resource that allows students to acquire the skills to independently create a Web site. This Internet resource can be used for forms of work in informatics in any educational institution during a pandemic.
\end{abstract}

International Journal of Health Sciences (C) 2022. This is an open access article under the CC BY-NC-ND license (https://creativecommons.org/licenses/by-nc-nd/4.0/).

\section{Contents}

Abstract

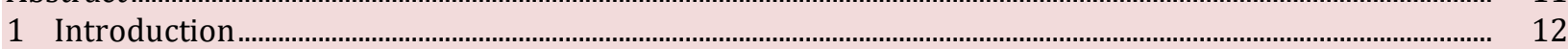

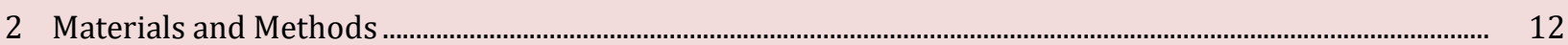

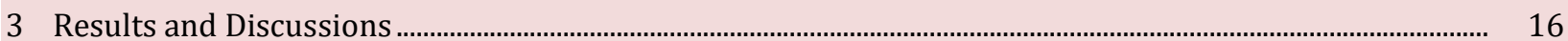

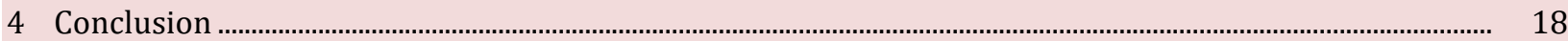

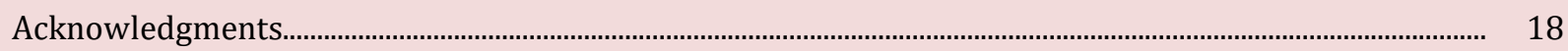

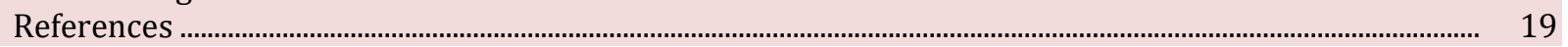

\footnotetext{
a Mykhailo Kotsiubynskyi State Pedagogical University, Vinnytsia, Ukraine

b Berdyansk State Pedagogical University, Berdyansk, Ukraine

c Kyiv National University of Culture and Arts, Kyiv, Ukraine

${ }^{d}$ Kyiv National University of Culture and Arts, Kyiv, Ukraine

e Kyiv National University of Culture and Arts, Kyiv, Ukraine
} 


\section{Introduction}

The modern period of the development of society is characterized by a strong influence of computer technologies on it, which penetrate all spheres of human activity, ensure the spread of information flows in society, forming a global information space. An integral and important part of these processes is the computerization of education. At present, a new education system is being formed in Russia, focused on entering the world's information and educational space. This process is accompanied by significant changes in the pedagogical theory and practice of the educational process associated with making adjustments to the content of teaching technologies, which should be adequate to modern technical capabilities and contribute to the child's harmonious entry into the information society.

One of the main mechanisms that ensure the modernization of Russian education is the informatization of education, which can be considered as a purposefully organized process of providing the education sector with methodology, technology, and practice for the creation and optimal use of scientific and pedagogical, educational and methodological developments focused on the implementation of the possibilities of information and communication technologies. applied in a comfortable and health-saving environment (Iasechko et al., 2021).

In this regard, it is necessary to form in students the foundations of competent work with information, skills in using information and communication technologies in the process of solving cognitive tasks and performing creative tasks in cognitive and educational activities, focused on collecting, searching, evaluating, selecting, organizing, storing, transmission and replication of information, presentation of the result. Distance learning is a set of technologies that ensure the delivery of the bulk of the studied material to the learners, the interactive interaction of learners and teachers in the learning process, providing learners with the opportunity to independently work on mastering the material being studied, as well as in the learning process.

Distance learning in informatics is aimed at achieving the general goal of learning - creating conditions conducive to the development of intellectual, creative, personal qualities of students, adaptation in society, taking into account individual and age characteristics within the framework of distance learning of students.

The congestion of the curriculum does not allow for computer science lessons more often than once a week. As a result, it is not always possible to study the most relevant topics and give the student an opportunity for self-development (Harris \& Sutton, 1986).

The solution to this problem is the creation of an Internet resource that will allow students to study the most interesting topics and carry out practical exercises, to provide the right to choose the most interesting topics (Ankem, 2004; Smith et al., 1999; Attamimi et al., 2020). It is distance learning that allows some students to overcome the barrier in communicating with a computer, others - in a comfortable environment, doing specific work, to consolidate the knowledge gained in the lesson, the third - to develop their creative abilities, both within the framework of the subject "Informatics" and other subject areas, using a computer as a technical tool. This article shows the use of Internet technologies, in particular distance learning technologies, for organizing independent work in computer science, which increases students' interest in the subject and develops a cognitive interest in general (Granell et al., 2016; Parikh \& Verma, 2002).

Purpose of the article: To develop a methodology for teaching informatics using Internet technologies and experimentally test the effectiveness of its use in secondary specialized educational institutions.

Research object: modern Internet technologies.

The subject of research: the process of teaching computer science in secondary specialized educational institutions using Internet technologies.

\section{Materials and Methods}

At present, the concept of pedagogical technology has firmly entered the pedagogical lexicon. However, there are great discrepancies in its understanding and use. Consider this definition from different authors. Pedagogical technology - a set of psychological and pedagogical attitudes that determine a special set and 
arrangement of forms, methods, methods, teaching methods, educational means; it is the organizational and methodological toolkit of the pedagogical process.

Pedagogical technology is a meaningful technique for the implementation of the educational process. Pedagogical technology is a description of the process of achieving the planned learning outcomes.

Technology is art, craftsmanship, skill, a combination of processing methods, state changes.

Teaching technology is an integral procedural part of the didactic system.

Pedagogical technology is a well-thought-out model of joint pedagogical activity in the design, organization, and conduct of the educational process with the unconditional provision of comfortable conditions for students and teachers. Pedagogical technology is a systematic method of creating, applying, and defining the entire process of teaching and assimilating knowledge, taking into account technical and human resources and their interaction, which aims to optimize the forms of education.

Pedagogical technology means the systemic totality and procedure for the functioning of all personal, instrumental, and methodological means used to achieve pedagogical goals. The concept of "pedagogical technology" in educational practice is used at three hierarchically subordinate levels:

- General pedagogical (general didactic) level: general pedagogical (general didactic, general educational) technology characterizes the integral educational process in a given region, educational institution, at a certain stage of education. Here, pedagogical technology is synonymous with the pedagogical system: it includes a set of goals, content, means, and methods of teaching, an algorithm for the activities of subjects, and objects of the process.

- Private methodological (subject) level: private subject pedagogical technology is used in the meaning of "private methodology", i.e. as a set of methods and means for the implementation of a certain content of education and upbringing within the framework of one subject, class, teacher (method of teaching subjects, method of compensatory learning, method of work of a teacher, educator).

- Local (modular) level: local technology is the technology of individual parts of the educational process, the solution of particular didactic and educational tasks (technology of certain types of activities, the formation of concepts, the education of individual personal qualities, the technology of the lesson, the assimilation of new knowledge, the technology of repetition and material control, technology of independent work, etc.).

There are also technological microstructures: techniques, links, elements, etc. Lining up in a logical technological chain, they form an integral pedagogical technology (technological process). The technological diagram is a conventional image of the technology, the process of dividing it into separate functional elements and designation of logical connections between them (Iasechko et al., 2021; Mufidah et al., 2021).

Technological map - a description of the process in the form of a step-by-step, step-by-step sequence of actions (often in graphical form) with an indication of the means used. Terminological nuances. In the literature and practice of schools, the term pedagogical technology is often used as a synonym for the concept of a pedagogical system. The concept of a system is broader than technology, and includes, in contrast to the latter, the subjects themselves and the object, activities.

There is also the use of shortcut terms, which is not entirely scientifically correct, which has become established in some technologies. Unfortunately, it is not always possible to avoid terminological inaccuracies that make it difficult for ponies to understand. In our understanding, pedagogical technology is a meaningful generalization that incorporates the meanings of all definitions of various authors (sources). The concept of "pedagogical technology" can be represented by three aspects:

- Scientific: pedagogical technologies - a part of pedagogical science that studies and develops goals, content, and teaching methods and designs pedagogical processes;

- Procedural and descriptive: a description (algorithm) of the process, a set of goals, content, methods, and means to achieve the planned learning outcomes;

Mokliuk, M., Popova, O., Soroka, M., Babchenko, Y., \& Ivashchenko, I. (2022). Internet technology as one of distance education during pandemic. International Journal of Health Sciences, 6(1), 11-20. https://doi.org/10.53730/ijhs.v6n1.2981 
- Procedurally effective: the implementation of the technological (pedagogical) process, the functioning of all personal, instrumental and methodological pedagogical tools.

Thus, pedagogical technology functions both as a science that investigates the most rational ways of teaching, and as a system of methods, principles and regulations, principles and regulations applied in teaching, and as a real learning process. In the theory and practice of educational institutions today, there are many options for the educational process. Each author and performer brings into the pedagogical process something of his own, individual, in connection with which they say that each specific technology is the author. One can agree with this opinion. However, many technologies, in terms of their goals, content, methods, and means used, have quite a lot of similarities and, according to these common features, can be classified into several generalized groups (Laurencin \& Walker, 2020).

In terms of essential and instrumentally significant properties (for example, target orientation, the nature of the teacher-student interaction, the organization of training), the following classes of pedagogical technologies are distinguished. According to the level of application, general pedagogical, particular methodological (subject) and local (modular) technologies are distinguished. On a philosophical basis: materialistic and idealistic, dialectical and metaphysical, scientific (scientistic) and religious, humanistic and antihuman, anthroposophical and theosophical, pragmatic and existentialist, free education and coercion, and other varieties (Tacconi, 1998; Widana et al., 2021).

According to the scientific concept of assimilation of experience, the following are distinguished: associativereflex, behavioristic, gestalt technologies, interiorization, developmental. We can also mention the less common technologies of neurolinguistic programming and suggestive (Kankhva et al., 2016). By focusing on personal structures: information technology (the formation of school knowledge, ability, skills in subjects); operating rooms (the formation of methods of mental action); emotional-artistic and emotional-moral (the formation of the sphere of aesthetic and moral relations), technologies of self-development (the formation of self-governing personality mechanisms); heuristic (development of creative abilities) and applied (formation of an effective and practical sphere). By the nature of the content and structure, technologies are called: teaching and upbringing, secular and religious, general educational and vocationally oriented, humanitarian and technocratic, various sectoral, special subject, as well as monotechnologies, complex and group, and differentiated teaching methods, when the teacher has penetrating technologies (Harris \& Sutton, 1986).

In monotechnologies, the entire educational process is based on anyone's priority, dominant idea, principle, concept, in complex - it is combined from elements of various monotechnologies (Asman et al., 2021). Technologies, the elements of which are most often included in other technologies and play the role of catalysts, activators for them, are called penetrating technologies. By the type of organization and management of the cognitive activity, such a classification of pedagogical systems (technologies) is proposed. The interaction of a teacher with a student (control) can be open-ended (uncontrolled and uncorrected student activity), cyclical (with control, self-control and mutual control), scattered (frontal) or directed (individual), and, finally, manual (verbal) or automated using the combination of these features determines the following types of technologies:

- classical lecture training (control - open, absent-minded manual);

- teaching with the help of audiovisual technical means (open, diffuse automated);

- the "consultant" system (open, directed, manual);

- teaching with the help of a textbook (open, directed, automated) - independent work;

- the system of "small groups" (cyclical, scattered manual) - group, differentiated ways of teaching;

- computer training (cyclical, scattered, automated);

- "tutor" system (cyclical, directed, manual) - individual training;

- "software training" (cyclical, directed, automated); for which there is a pre-compiled program.

In practice, various combinations of these monodidactic systems usually appear, the most common of which are:

- The traditional classical classroom-lesson system, which is a combination of a lecture method of presentation and independent work with a book (didachography);

- Modern traditional teaching using didachography in combination with technical means; 
- Group and differentiated teaching methods, when the teacher has the opportunity to exchange information with the entire group, as well as pay attention to individual students as a tutor;

- Programmed learning based on adaptive program control with partial use of all other types.

A fundamentally important aspect in pedagogical technology is the position of the child in the educational process, the attitude of adults towards the child. Several types of technologies stand out here:

- The traditional classical classroom-lesson system, which is a combination of a lecture method of presentation and independent work with a book (didachography);

- Modern traditional teaching using didachography in combination with technical means;

- Group and differentiated teaching methods, when the teacher has the opportunity to exchange information with the whole group, as well as pay attention to individual students as a tutor;

- Programmed learning based on adaptive program control with partial use of all other types.

A fundamentally important aspect of pedagogical technology is the position of the child in the educational process, the attitude of adults towards the child. Several types of technologies stand out here:

- Authoritarian technologies, in which the teacher is the sole subject of the educational process, and the student is only an "object", "cog". They are distinguished by the rigid organization of school life, suppression of the initiative and independence of students, the use of demands, and coercion;

- Didactocentric technologies are distinguished by a high degree of inattention to the personality of the child, in which the subject also dominates - the object relationship of the teacher and the student, the priority of teaching over education, and didactic means are considered the most important factors in the formation of personality. Didactocentric technologies are called technocratic in many sources; however, the latter term, in contrast to the first, refers more to the nature of the content, and not to the style of pedagogical relations;

- Personality-oriented technologies put the child's personality at the center of the entire school educational system, ensuring comfortable, conflict-free, and safe conditions for its development, the realization of its natural potentials. The child's personality in this technology is not only a subject, but also a priority subject; it is the goal of the educational system, and not a means to achieve any abstract goal (which is the case in authoritarian and didactocentric technologies). Such technologies are also called anthropocentric;

Thus, personality-oriented technologies are characterized by anthropocentricity, humanistic and psychotherapeutic orientation and are aimed at the versatile, free, and creative development of the child. Within the framework of personality-oriented technologies, human-personal technologies, technologies of cooperation, and technologies of free education are distinguished as independent directions:

- Human-personal technologies are distinguished primarily by their humanistic essence, psychotherapeutic focus on supporting the individual, helping her. They "profess" the ideas of all-round respect and love for the child, optimistic faith in his creative powers, rejecting coercion;

- Technologies of cooperation realize democracy, equality, partnership in the subject - the subject relationship of the teacher and the child. The teacher and students jointly develop goals, content, and assess, being in a state of cooperation;

- Technologies of free upbringing focus on providing the child with freedom of choice and independence in a greater or lesser sphere of his life. Making a choice, the child realizes the position of the subject in the best way, going to the result from internal motivation, and not from an external influence;

- Esoteric technologies are based on the doctrine of esoteric ("unconscious, subconscious") knowledge the truth and the ways leading to it. The pedagogical process is not a message, not communication, but an introduction to the Truth. In the esoteric paradigm, the person (child) himself becomes the center of information interaction with the Universe (POLAT, 2021).

Mokliuk, M., Popova, O., Soroka, M., Babchenko, Y., \& Ivashchenko, I. (2022). Internet technology as one of distance education during pandemic. International Journal of Health Sciences, 6(1), 11-20. https://doi.org/10.53730/ijhs.v6n1.2981 
The method, method, teaching tool determine the names of many existing technologies: dogmatic, reproductive, explanatory-illustrative, programmed teaching, problem learning, developmental learning, self-development learning, dialogical, communicative, playful, creative, etc. According to the category of students, the most important and original are:

- Mass (traditional) school technology, designed for the average student;

- Technologies of an advanced level (in-depth study of subjects, gymnasium, lyceum, special education, etc.);

- Technologies of compensatory education (pedagogical correction, support, alignment, etc.);

- Various victimological technologies (deaf-, ortho-, typhlo- oligophrenopedagogy);

- Technologies for working with deviant (difficult and gifted) children within the framework of the mass school (Iasechko et al., 2021).

And, finally, the names of a large class of modern technologies are endowed with the content of those modernizations and modifications to which the existing traditional system undergoes them. Monodidactic technologies are used very rarely. Usually, the educational process is structured in such a way that some polydidactic technology is constructed that unites and integrates some elements of various monotechnologies based on some priority original author's idea. It is essential that combined didactic technology can have qualities that exceed the qualities of each of the technologies included in it (Komilova et al., 2021).

Usually, combined technology is called according to the idea (monotechnology) that characterizes the main modernization, does the greatest in achieving the learning goals. In the direction of modernization of the traditional system, the following groups of technologies can be distinguished.

\section{Results and Discussions}

Specialists on strategic problems of education call distance learning the educational system of the 21 st century. A huge stake has been placed on it today. The relevance of the topic of distance learning lies in the fact that the results of social progress, previously concentrated in the field of technology, are now concentrated in the information sphere. The era of computer science has arrived. The stage of its development at the moment can be characterized as telecommunication. This is the area of communication, information, and knowledge. Based on the fact that professional knowledge is aging very quickly, it is necessary to constantly improve it. Distance learning allows today to create systems of mass continuous self-learning, general exchange of information, regardless of time and space zones. In addition, distance education systems provide equal opportunities for all people, regardless of social status (schoolchildren, students, civilian and military, unemployed, etc.) in any region of the country and abroad to exercise human rights to education and information. It is this system that can most adequately and flexibly respond to the needs of society and ensure the implementation of the constitutional right to education of every citizen of the country (Rovai, 2003; Rovai \& Downey, 2010).

The first direction, that is, the shell for classes. It is like a study room in which all training sessions take place. Here, easy access to training sessions, to various educational literature of the course should be provided, the terms for passing each stage are indicated. A communication platform is required (a place for students to discuss problems, as well as a place for consultations and in common with the teacher). The presence in the program of a database with contact addresses (for example, an e-mail address or, in extreme cases, phone numbers) of all students on the course, the teacher and the administrator of the program, organizes constant communication. Each course participant should be able to store all their working material on the server (where the course is located). The teacher always has the opportunity to supervise students at every stage of training. Naturally, there must be constant access to the course shell via the Internet, so that any student can have access to work with the course at any time convenient for him (Iasechko et al., 2021).

There are many distance learning frameworks on the Internet today. Visually, they are all different, but many of them have common features that were formed in connection with the originality of distance learning. A modern distance learning system should be designed to work on any network, on any platform, have a web interface, and store data in a standardized format for storing educational information. The technical implementation of shells is often aimed at developing integrated solutions, i.e. to create a software environment 
that provides an interconnected and coordinated solution to the heterogeneous tasks of the distance learning process, namely:

- Collection and storage of the necessary information in various forms of its presentation, it's operational updating;

- Issuance of information to users;

- Authorization of access to information by users and implementation of a multi-level information security system;

- System administration;

- Efficient and fast creation of information resources by users.

The results of the test control of the distance course should give a true assessment of knowledge. For test materials, it is very important to select different forms of assignments for different types of activities and depending on the originality of the course. Thus, for the organization of distance learning, it is necessary to solve the following organizational and technical problems:

- Development of a unified standard (format) for storing educational information resources;

- Providing effective means of communication between teachers and students;

- Creation of management tools for the educational process of distance education;

- Effective means of planning the educational process (curriculum);

- The problem of effective presentation of educational material;

- Creation of means of ensuring the joint work of students;

- Providing remote access to information resources.

In general, these problems should and can be solved by creating a distance learning system with an architecture based on new technologies, taking into account the shortcomings of previous systems, as well as the current and future needs of distance education (Kotsiantis et al., 2010). Thus, our task is to create a shell that provides both informational and communication capabilities and is aimed at:

- Gaining access to educational material;

- Communication in the discussion forum (item Video broadcast);

- Knowledge control (test);

- The possibility of informing the teacher about the successful (or lagging) completion of the next lesson (stage);

- Obtaining free access to additional material (Blog item) or the list of replenished (including students) literature with annotations (Information item);

- The ability to view the terms (item Information) view the e-mail addresses and home pages of all members of the group (item Contacts);

- The ability to write a letter to any trainee in the group;

- Once a week (by agreement of time) for one hour, all course participants should gather for an interactive conversation (Videoconference) - to discuss and solve problems.

A teacher or course moderator can organize a course: add or remove classes, change dates, etc. (Information item). Only the specialist who configures this shell has access to the specialist work area. For training sessions, you can access any type of file (for example, text, sound, or video). In this shell, all the possibilities for the training of trainees with Internet access are organized. Any interested teacher can contribute their distance course to teach students over the Internet without installing any additional programs.

Mokliuk, M., Popova, O., Soroka, M., Babchenko, Y., \& Ivashchenko, I. (2022). Internet technology as one of distance education during pandemic. International Journal of Health Sciences, 6(1), 11-20. https://doi.org/10.53730/ijhs.v6n1.2981 


\section{Conclusion}

The article discusses aspects of the organization of distance learning. The curriculum for the computer science course was analyzed. Based on the analysis, it was concluded that in the course of secondary vocational education, issues of image processing are not sufficiently dedicated, and too little time is devoted to the topic of web programming. Based on the foregoing, we can conclude that students like to study the topic of web programming, students are very much interested in studying this topic. It is distance learning that is an undoubted advantage in teaching students. It can be concluded that this course develops students' abilities, increases motivation, and raises self-esteem.

The results of the study confirmed the hypothesis: that if we organize the teaching of students using Internet technologies, then this will deepen the knowledge of the program material in computer science and, as a result, will increase the efficiency of the educational process as a whole, will increase the motivation of students to the subject, and also contribute to the development of students' ability to self-development. self-education.

Improving efficiency is impossible without creating new forms of student learning. In this regard, much attention is paid to independent work today. An important role here is played by students' independent work with a computer, work on the information object itself. According to the results of the study, it can be concluded that the study of material on informatics is more efficiently carried out using Internet technologies. Students' interest in the subject is increasing. Self-esteem and student motivation increase.

\section{Acknowledgments}

We are grateful to two anonymous reviewers for their valuable comments on the earlier version of this paper. 


\section{References}

Ankem, K. (2004). Adoption of Internet resource-based value-added processes by faculty in LIS education. Library \& information science research, 26(4), 482-500. https://doi.org/10.1016/j.lisr.2004.04.008

Asman, A., Asman, A., \& Dewi, A. K. (2021). Community nursing strategies for tourism health families during COVID-19 pandemic. International Journal of Health Sciences, 5(3), 224-231. https://doi.org/10.53730/ijhs.v5n3.1449

Attamimi, H. R. ., Lestari, Y. ., Situmorang, B. . H. L. ., Antari, G. Y. ., \& Nugrawati, N. . (2020). Application of habituation method in germas interventionsin: the pandemic time COVID-19. International Journal of Health \& Medical Sciences, 3(1), 98-104.

Granell, C., Havlik, D., Schade, S., Sabeur, Z., Delaney, C., Pielorz, J., ... \& Mon, J. L. (2016). Future Internet technologies for environmental applications. Environmental Modelling \& Software, 78, 1-15. https://doi.org/10.1016/j.envsoft.2015.12.015

Harris, S. G., \& Sutton, R. I. (1986). Functions of parting ceremonies in dying organizations. Academy of Management journal, 29(1), 5-30.

Iasechko, M., Iasechko, S., \& Smyrnova, I. (2021). Pedagogical aspects of self-development of distance education students in Ukraine. Laplage In Review, 7, 316-323.

Iasechko, M., Kharlamov, M., Gontarenko, L., Skrypchuk, H., Fadyeyeva, K., \& Sviatnaia, O. (2021). Artificial intelligence as a technology of the future at the present stage of development of society.

Iasechko, M., Shelukhin, O., Maranov, A., Lukianenko, S., Basarab, O., \& Hutchenko, O. (2021). Evaluation of The Use of Inertial Navigation Systems to Improve The Accuracy of Object Navigation. International Journal of Computer Science \& Network Security, 21(3), 71-75.

Kankhva, V., Uvarova, S., \& Belyaeva, S. (2016). Development of the scientific and methodological assessment tools of sustainability of the investment and construction complex in Russia and its structural elements in terms of organizational and economic changes. Procedia Engineering, 165, 1046-1051. https://doi.org/10.1016/j.proeng.2016.11.818

Komilova, N. K., Rakhimova, T., Allaberdiev, R. K., Mirzaeva, G. S., \& Egamberdiyeva, U. T. (2021). Ecological situation: the role of education and spirituality in improving health of population. International Journal of Health Sciences, 5(3), 302-312. https://doi.org/10.53730/ijhs.v5n3.1512

Kotsiantis, S., Patriarcheas, K., \& Xenos, M. (2010). A combinational incremental ensemble of classifiers as a technique for predicting students' performance in distance education. Knowledge-Based Systems, 23(6), 529535. https://doi.org/10.1016/j.knosys.2010.03.010

Laurencin, C. T., \& Walker, J. M. (2020). A Pandemic on a Pandemic: Racism and COVID-19 in Blacks. Cell systems, 11(1), 9-10. https://doi.org/10.1016/j.cels.2020.07.002

Mufidah, N., Suhron, M., \& Wahyudi, R. (2021). Analysis of post-stroke anxiety (PSA) factors during the COVID19 pandemic in Indonesia. International Journal of Health \& Medical Sciences, 5(1), 1-6.

Parikh, M., \& Verma, S. (2002). Utilizing Internet technologies to support learning: an empirical analysis. International Journal of Information Management, 22(1), 27-46. https://doi.org/10.1016/S02684012(01)00038-X

POLAT, E.S. (2021). Distance learning models.

Rovai, A. P. (2003). In search of higher persistence rates in distance education online programs. The internet and higher education, 6(1), 1-16. https://doi.org/10.1016/S1096-7516(02)00158-6

Rovai, A. P., \& Downey, J. R. (2010). Why some distance education programs fail while others succeed in a global environment. The Internet and Higher Education, 13(3), 141-147. https://doi.org/10.1016/j.iheduc.2009.07.001

Smith, B. R., Huff, D. S., \& Johnson, G. A. (1999). Magnetic resonance imaging of embryos: an Internet resource for the study of embryonic development. Computerized Medical Imaging and Graphics, 23(1), 33-40. https://doi.org/10.1016/S0895-6111(98)00061-5

Tacconi, L. (1998). Scientific methodology for ecological economics. Ecological Economics, 27(1), 91-105. https://doi.org/10.1016/S0921-8009(97)00134-1

Widana, I.K., Sumetri, N.W., Sutapa, I.K., Suryasa, W. (2021). Anthropometric measures for better cardiovascular and musculoskeletal health. Computer Applications in Engineering Education, 29(3), 550-561. https://doi.org/10.1002/cae.22202

Mokliuk, M., Popova, O., Soroka, M., Babchenko, Y., \& Ivashchenko, I. (2022). Internet technology as one of distance education during pandemic. International Journal of Health Sciences, 6(1), 11-20. https://doi.org/10.53730/ijhs.v6n1.2981 


\section{Biography of Authors}

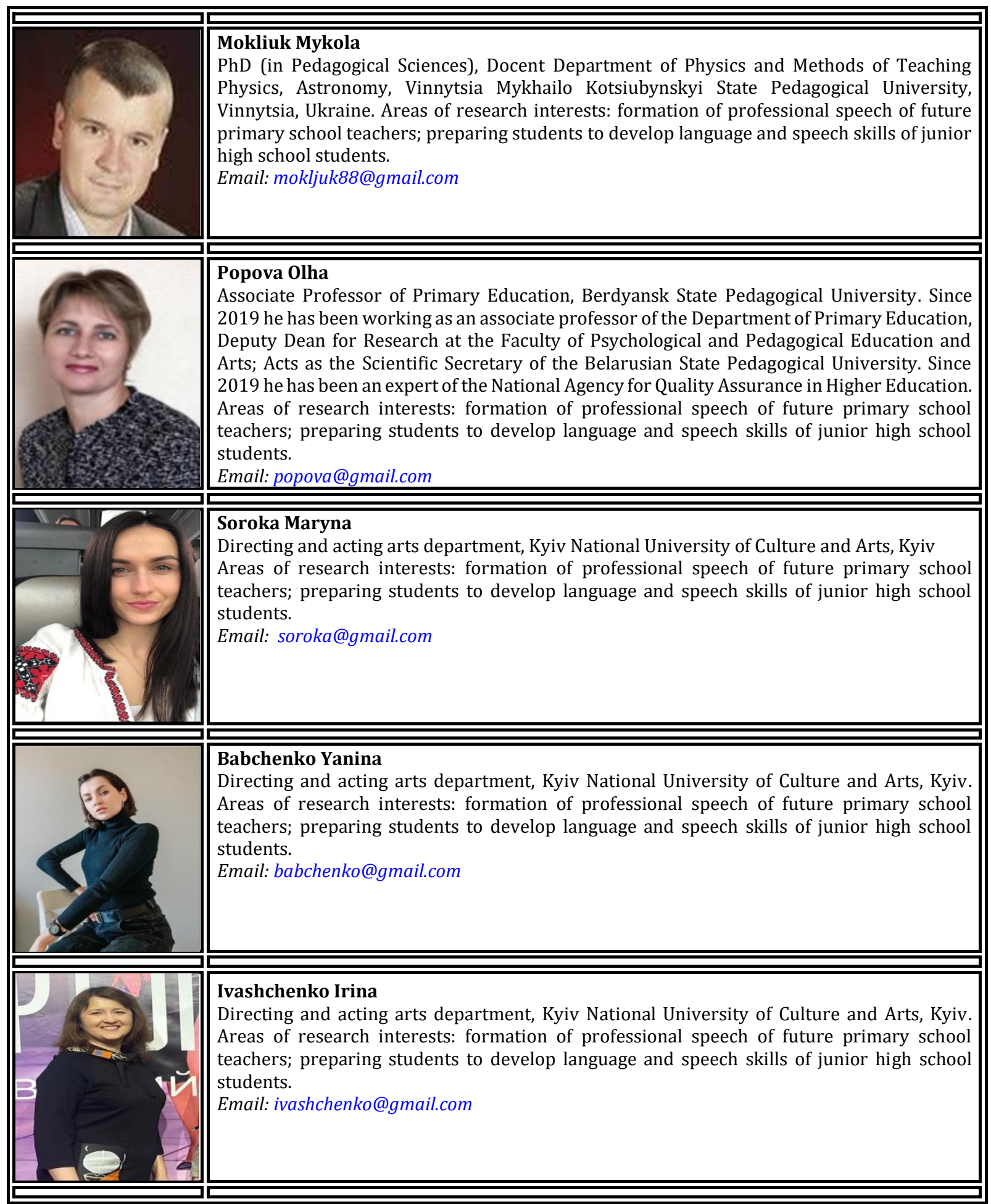

